\title{
Acclimation of Trichodesmium erythraeum ISM101 to high and low irradiance analysed on the physiological, biophysical and biochemical level
}

\author{
Elisa Andresen ${ }^{1}$, Jens Lohscheider ${ }^{1}$, Eva Šetlikova ${ }^{2,3}$, Iwona Adamska ${ }^{1}$, Miloslav Šimek ${ }^{4}$ and Hendrik Küpper ${ }^{1,2}$ \\ ${ }^{1}$ Universität Konstanz, Mathematisch-Naturwissenschaftliche Sektion, Fachbereich Biologie, D78457 Konstanz, Germany; ${ }^{2}$ Faculty of Science and Institute \\ of Physical Biology, University of South Bohemia, Branišovská 31, CZ-370 05 České Budějovice, Czech Republic; ${ }^{3}$ Department of Autotrophic Micro- \\ organisms, Institute of Microbiology, Academy of Sciences of the Czech Republic, Opatovický Mlýn, CZ-37981 Treboň, Czech Republic; ${ }^{4}$ Biology Centre \\ AS CR, v. v. i. Institute of Soil Biology and Faculty of Science, University of South Bohemia, Na Sadkach 7, CZ-37005 České Budějovice, Czech Republic
}

Author for correspondence: Hendrik Küpper

Tel: +49 7531884112

Email: hendrik.kuepper@uni-konstanz.de

Received: 15 June 2009

Accepted: 2 September 2009

\section{Summary}

- As the nonheterocystous diazotrophic cyanobacterium Trichodesmium lives both at the ocean surface and deep in the water column, it has to acclimate to vastly different irradiances. Here, we investigate its strategy of light acclimation in several ways.

- In this study, we used spectrally resolved fluorescence kinetic microscopy to investigate the biophysics of photosynthesis in individual cells, analysed cell extracts for pigment and phycobiliprotein composition, measured nitrogenase activity and the abundance of key proteins, and assayed protein synthesis/degradation by radioactive labelling.

- After acclimation to high light, Trichodesmium grew faster at $1000 \mu \mathrm{mol}$ $\mathrm{m}^{-2} \mathrm{~s}^{-1}$ than at $100 \mu \mathrm{mol} \mathrm{m} \mathrm{m}^{-2} \mathrm{~s}^{-1}$. This acclimation was associated with decreasing cell diameter, faster protein turnover, the down-regulation of light-harvesting pigments and the outer part of the phycobiliprotein antenna, the up-regulation of light-protective carotenoids, changes in the coupling of phycobilisomes to the reaction centres and in the coupling of individual phycobiliproteins to the phycobilisomes. The latter was particularly interesting, as it represents an as yet unreported light acclimation strategy.

- Only in the low light-acclimated culture and only after the onset of actinic light did phycourobilin and phycoerythrin contribute to photochemical fluorescence quenching, showing that these phycobiliproteins may become quickly (in seconds) very closely coupled to photosystem II. This fast reversible coupling also became visible in the nonphotochemical changes of the fluorescence quantum yield.

\section{Introduction}

The biological fixation of atmospheric nitrogen is performed by certain cyanobacteria when bioavailable forms of nitrogen (mostly nitrate and ammonia) are limited. As the enzyme nitrogenase, which catalyses the fixation of dinitrogen, is directly and irreversibly inactivated when exposed to oxygen (reviewed by Postgate, 1998), the process can only take place under anaerobic conditions. Different cyanobacteria have evolved different ways to protect

A tribute in memory of our friend Ivan Šetlikk (1928-2009). the nitrogenase from oxygenic damage (reviewed by Berman-Frank et al., 2003). A spatial separation of oxygenevolving and nitrogen-fixing processes is found in heterocystous cyanobacteria (e.g. Anabaena, Nostoc; Allen \& Arnon, 1955); a temporal separation of the two processes (photosynthesis in the photoperiod, nitrogen fixation in the night) in the same cells occurs in Cyanotheca and Lyngbya (Jones, 1990). Cyanobacteria of the genus Trichodesmium, inhabiting oligotrophic tropical and subtropical seas and contributing the largest part of nitrogen fixation in the oceans (Capone et al., 1997, 2005; Westberry \& Siegel, 2006), do not possess heterocysts, and nitrogen 
fixation is not restricted to the dark period. Although there is no permanent cell differentiation separating photosynthesis from nitrogenase, nitrogenase is expressed in only a subset (10-20\%) of cells within a filament (trichome) (Fredriksson \& Bergman, 1995). Protection from irreversible damage by oxygen involves two main processes. During the period of nitrogen fixation, the respiration rate is much higher (Kana, 1993; Carpenter \& Roenneberg, 1995), but the oxygen-consuming, photosystem II (PSII)dependent Mehler reaction seems to have a much higher impact (Kana, 1993). This reaction also provides energy for nitrogen fixation. In this way, in Trichodesmium, nitrogen fixation is dependent on PSII-mediated photosynthesis and can therefore be blocked by PSII inhibitors, such as 3 (3,4-dichlorophenyl)-1,1-dimethylurea (Berman-Frank et al., 2001).

Previous experiments using fluorescence kinetic microscopy (FKM; Küpper et al., 2000a, 2007a) have shown that PSII activity in Trichodesmium is homogeneously high in all cells of a trichome during most of the day (Berman-Frank et al., 2001; Küpper et al., 2004, 2008, 2009). During nitrogen fixation, cells with an elevated basic chlorophyll (Chl) fluorescence yield $\left(F_{0}\right)$, called 'bright cells', appear (Berman-Frank et al., 2001). Two types of such 'bright cells' were found, but only one type is connected with nitrogen fixation (type I) (Küpper et al., 2004). The other type (type II, 'very bright cells') can also occur without the presence of nitrogenase activity, but are related to stress (Küpper et al., 2004, 2008). In addition, cells with unusually low fluorescence and photochemical fluorescence quenching were found during and directly after the diazotrophic period (Küpper et al., 2004). Reversible switches between different fluorescence levels can, in part, occur very rapidly (Küpper et al., 2004, 2009), excluding pigment or protein synthesis as their cause. Using spectrally resolved, single-cell measurements of fluorescence kinetics by fluorescence kinetic microscopy (Küpper et al., 2007a), it has been shown recently that these changes in $F_{0}$ are caused by reversible coupling of phycobiliproteins (Küpper et al., 2009). This indicates a transition of the classical state, that is movement of the complete phycobilisomes between photosystem $I$ (PSI) and PSII, and reversible coupling of individual isoforms, in particular phycourobilin (PUB). Moreover, it involves coupling to either PSI or PSII, as well as complete uncoupling. In this way, it was found that the diazotrophic bright I cells are characterized by a large PSII-associated antenna with a high proportion of PUB, whereas the bright II cells are characterised by completely uncoupled phycobiliproteins dissociated from the phycobilisome complex.

In the current study, we evaluated how Trichodesmium erythraeum IMS101 acclimates to different irradiances, and how this affects the whole process of regulation of photosynthesis for nitrogen fixation. We used spectrally resolved, single-cell measurements of fluorescence kinetics by FKM and analysed them quantitatively for contributions of individual components of the antenna in order to determine whether reversible (un)coupling also plays a role in the acclimation to different light regimes. Further, we used radioactive labelling experiments to trace protein synthesis and degradation rates, and employed Western blots to analyse the changes in protein expression levels in response to the different light regimes.

\section{Materials and Methods}

\section{Cultivation}

Trichodesmium erythraeum strain IMS101 was grown in a continuous chemostat culture with a growth medium (called YBCHK) containing the following components: $420 \mathrm{~mm} \mathrm{NaCl}, 10 \mathrm{mM} \mathrm{KCl}, 20 \mathrm{mM} \mathrm{MgCl}, 10 \mathrm{~mm}$ $\mathrm{CaCl}_{2}, 25 \mathrm{~mm} \mathrm{MgSO}_{4}, 2.5 \mathrm{~mm} \mathrm{NaHCO}, 780 \mu \mathrm{M} \mathrm{KBr}$ $50 \mu \mathrm{KH}_{2} \mathrm{PO}_{4}, 68 \mu \mathrm{M} \mathrm{NaF}, 25 \mu \mathrm{M} \mathrm{LiCl}, 2 \mu \mathrm{M} \mathrm{RbCl}$, $1 \mu \mathrm{m}$ Fe-EDTA, $450 \mathrm{~nm} \mathrm{NaIO}, 80 \mathrm{~nm} \mathrm{Na} \mathrm{MoO}_{4}, 20 \mathrm{~nm}$ $\mathrm{MnCl}_{2}, 7 \mathrm{~nm} \mathrm{NiSO}_{4}, 2.5 \mathrm{~nm} \mathrm{CoCl}_{2}, 1 \mathrm{~nm} \mathrm{CuSO}_{4}$, dissolved in re-distilled water. The $\mathrm{pH}$ was adjusted to 8.2 with $\mathrm{NaOH}$ and the medium was sterilized by autoclaving. The flow rate of the medium was chosen to achieve an optical density at $750 \mathrm{~nm}\left(\mathrm{OD}_{750 \mathrm{~nm}}\right)$ of the cultures of 0.5 , resulting (dependent on the level of growth irradiance, see below) in a flow of $c .0 .25-1.5 \mathrm{I} \mathrm{d}^{-1}$ in 41 chemostats (specific growth rate $\mu=$ dilution rate $D=1.51 \mathrm{~d}^{-1} \times 4 \mathrm{I}^{-1}=$ $\left.0.38 \mathrm{~d}^{-1}\right)$. The chemostats were aerated with air and the cultures were maintained in a $12 \mathrm{~h}: 12 \mathrm{~h}$ light : dark cycle (light from 08:00 to 20:00 h local time). The photon flux density during the light period followed a sinusoidal cycle simulating natural conditions. The experiment was replicated with two independent chemostats per irradiance level. From each chemostat, at least three complete daily cycles were sampled, distributed over a period of c. 1 month, which means that, altogether, six sets of cell populations were sampled per irradiance. We chose two different light conditions representing the irradiances that Trichodesmium meets in the ocean: high light (HL) with a peak intensity of c. $1000 \mu \mathrm{mol} \mathrm{m} \mathrm{m}^{-2} \mathrm{~s}^{-1}$, similar to irradiances at the water surface, and low light ( $\mathrm{LL}, 100 \mu \mathrm{mol} \mathrm{m} \mathrm{m}^{-2} \mathrm{~s}^{-1}$ ), representing conditions deeper in the water column where Trichodesmium can still grow. The light source was a panel of OSRAM Dulux L 55 W/12-950 (Osram GmbH, Munich, Germany, http://www.osram.com) fluorescent tubes. The LL conditions used in this study are also similar to the irradiances used in most other Trichodesmium laboratory studies found in the literature, including our earlier studies (Berman-Frank et al., 2001; Küpper et al., 2004). In our more recent studies, we employed irradiances between the two extremes used now (Küpper et al., 2008 used $300 \mu \mathrm{mol} \mathrm{m} \mathrm{m}^{-2} \mathrm{~s}^{-1}$ peak irradiance at noon; Küpper et al., 2009 employed $600 \mu \mathrm{mol}$ $\mathrm{m}^{-2} \mathrm{~s}^{-1}$ peak irradiance at noon). 


\section{Sampling times for in vivo measurements}

Samples for the measurement of nitrogenase activity and FKM analyses were taken five times a day: 07:00 h in the dark before the onset of the light period; $10: 00 \mathrm{~h}$ before pigment and enzyme synthesis; $13: 30 \mathrm{~h}$ in the middle of the light period; $17: 00 \mathrm{~h}$, the time of nitrogenase decline; and $20: 30 \mathrm{~h}$ after the end of the light period.

\section{Analysis of Chl, carotenoids and phycobilisomes in cell extracts}

Chl and carotenoids were extracted with $100 \%$ acetone after filtering 40 or $80 \mathrm{ml}$ (depending on $\mathrm{OD}$ ) of culture through $25 \mathrm{~mm}$ GF/F glass fibre filters (Whatman, Dassel, Germany, http://www.whatman.com), freezing the filters in liquid nitrogen and lyophilizing them. After $1 \mathrm{~d}$ of extraction at $4^{\circ} \mathrm{C}$ in the dark, absorbance spectra from 350 to $750 \mathrm{~nm}$ were recorded in $0.2 \mathrm{~nm}$ intervals at an optical bandwidth (slit) of $1 \mathrm{~nm}$. From these spectra, carotenoids and $\mathrm{Chl}$ were analysed using the Gauss-Peak-Spectra method of Küpper et al. (2007b).

Phycobiliproteins were extracted after completion of the acetone extraction described above, which removed, together with the pigments, the membranes from the cells. This pretreatment made the phycobilisomes easily accessible for extraction by incubation with phosphate-buffered saline ( $40 \mathrm{~g} \mathrm{l}^{-1} \mathrm{NaCl} ; 1 \mathrm{~g} \mathrm{l}^{-1} \mathrm{KCl} ; 7.2 \mathrm{~g} \mathrm{I}^{-1} \mathrm{Na}_{2} \mathrm{HPO}_{4} ; 1.2 \mathrm{~g} \mathrm{l}^{-1}$ $\left.\mathrm{KH}_{2} \mathrm{PO}_{4}\right)$ for $1 \mathrm{~d}$ at $4^{\circ} \mathrm{C}$ in the dark. The spectra of these extracts were recorded in the same way as those of the acetone extracts. The contents of the different phycobiliproteins were determined in the same way as Chl and carotenoids, using the Gauss-Peak-Spectra obtained from purified Trichodesmium phycobiliproteins (Küpper et al., 2009).

\section{Preparation of samples for FKM measurements}

Depending on the OD of the culture, $2-5 \mathrm{ml}$ of cell suspension were taken from the chemostat cultures and filtered through a membrane filter to remove the medium. The cells were resuspended by washing the filter in $50 \mu \mathrm{l}$ of YBCHK placed on the window of the measuring chamber (details in Küpper et al., 2000a, 2004, 2008). Fifty microlitres of agarose (1.5\% SeaKem Gold agarose in YBCHK) were mixed with the medium drop containing the cyanobacteria and covered with gas-permeable cellophane. The chamber was temperature controlled and the medium was pumped through at $30 \mathrm{ml} \mathrm{min}{ }^{-1}\left(27^{\circ} \mathrm{C}\right)$, as described previously (Küpper et al., 2000a, 2004, 2008, 2009).

\section{FKM measurements}

The spectrally resolved fluorescence kinetics on a singlecell level were measured as described in Küpper et al. (2007a, 2009), with excitation at $400-505 \mathrm{~nm}$ (blue) or $340-390 \mathrm{~nm}$ (UV) and fluorescence detection from 515 to $800 \mathrm{~nm}$, adjusted by the exciting light-emitting diodes (LEDs) and filter sets (Küpper et al., 2008; UV excitation added as new). All measurements were performed following a previously optimized protocol (Küpper et al., 2007a, 2008). The protocol was optimized so that the times of dark relaxation and actinic irradiance were sufficient to reach a 'steady state' in terms of switching between darkadapted and light-adapted (and vice versa) states. Further, it was optimized in terms of irradiance levels (measuring nonactinic light, medium-intensity noninhibitory actinic light, nondamaging saturating light but sufficient to close all reaction centres) and in the spacing of the flashes of saturating light that are needed for the analysis of photochemical and nonphotochemical quenching. Details on $\mathrm{Chl}$ fluorescence kinetic measurements in general, including the explanation of the technical terms and different types of light needed for measurement, can be found in recent reviews, such as Maxwell \& Johnson (2000). Each measurement lasted $300 \mathrm{~s}$. $F_{\mathrm{m}}$ was measured by providing a saturating light pulse of c. $4000 \mu \mathrm{mol} \mathrm{m} \mathrm{m}^{-2} \mathrm{~s}^{-1}$ and $600 \mathrm{~ms}$ in the third second of measurement. After $90 \mathrm{~s}$ of darkness, $F_{0}$ was measured for $5 \mathrm{~s}\left(5 \mu \mathrm{mol} \mathrm{m}{ }^{-2} \mathrm{~s}^{-1}\right.$, tested to be nonactinic for Trichodesmium). This was followed by $100 \mathrm{~s}$ of actinic light with an irradiance of 400 $\mu \mathrm{mol} \mathrm{m} \mathrm{m}^{-2} \mathrm{~s}^{-1}$ to analyse the Kautsky induction. To measure the dark relaxation, $100 \mathrm{~s}$ without actinic light were recorded. Additional $600 \mathrm{~ms}$ saturating pulses were given during the exposure to actinic light (to measure photochemical quenching), as well as in the relaxation period (to measure nonphotochemical quenching). For the analysis of the spectral kinetics, the excitation range $(400-505 \mathrm{~nm})$ was recorded, together with the fluorescence range $(505-800 \mathrm{~nm})$ as an internal standard of reflected light used to calculate the relative fluorescence quantum yields. In the system used for our previous study (Küpper et al., 2009), the light source consisting of two white LEDs exhibited a slight shift of the spectrum between the measuring, actinic and saturating light pulses because of the heating of the LEDs. This made the measurements of photochemical quenching unreliable, as discussed in that publication, so that we did not use the photochemical quenching data at that time. In the present work, the two white LEDs were replaced by an array of five LEDs (UV, blue, green, white, far red) each for the actinic/saturating and measuring light pulses, with individual timing and intensity control of each LED. This modification drastically reduced the spectral shift problem, so that we could include the photochemical quenching measurements in our results. The kinetics were analysed as described in Küpper et al. $(2007 \mathrm{a}, 2009)$ using FluorCam7 software from Photon Systems Instruments (Brno, Czech Republic, http://www.psi.cz). 


\section{Nitrogenase activity}

Nitrogenase activity was measured using the acetylene reduction assay (Dilworth, 1966). Fifteen millilitre samples were taken five times a day (see above) and incubated in $70 \mathrm{ml}$ serum bottles. Ten millilitres of acetylene were added to the $55 \mathrm{ml}$ air in the bottles. The samples were incubated for $1 \mathrm{~h}$ in an incubator with the same temperature and light: dark cycle as the main cultures. Both acclimation states (HL and LL cultures) were measured at both irradiance levels in order to determine how longterm acclimation processes changed the efficiency of nitrogen fixation (i.e. nitrogen fixation 'output' compared with light 'input') at the respective irradiance levels. After the incubation time, $2 \mathrm{ml}$ of the gas was taken out and analysed by gas chromatography (Hewlett Packard HP 5890 Series II (Agilent Technologies, Inc, Santa Clara, CA, USA), equipped with flame ionization detector and packed steel $1.8 \mathrm{~m}$ column with Porapak N). The same was performed with a control containing only $15 \mathrm{ml}$ of YBCHK medium to check for acetylene reduction not produced by Trichodesmium.

\section{Protein extraction and immunoblot analysis}

Protein sample preparation for immunoblot analysis was performed as described in Küpper et al. (2008). All antibodies were applied in dilutions recommended by the manufacturer.

\section{Labelling of proteins with ${ }^{35} \mathrm{~S}$-methionine}

For pulse labelling, $100-150 \mathrm{ml}$ of cultures grown in LL $\left(100 \mu \mathrm{mol} \mathrm{m} \mathrm{m}^{-2} \mathrm{~s}^{-1}\right)$ or $\mathrm{HL}\left(1000 \mu \mathrm{mol} \mathrm{m}^{-2} \mathrm{~s}^{-1}\right)$ conditions were harvested at the end of the dark phase $(07: 00 \mathrm{~h})$, in the middle $(13: 30 \mathrm{~h})$ and at the end $(17: 00 \mathrm{~h})$ of the light phase, and the cells were collected by filtration on a nucleopore track-etch membrane with $5 \mu \mathrm{m}$ pores (Whatman). The collected cells were resuspended in fresh YBCHK medium to a Chl concentration of $3 \mu \mathrm{g} \mathrm{ml}^{-1}$ and incubated under LL or HL conditions, respectively, for $1 \mathrm{~h}$ before the addition of $20 \mu \mathrm{Ci} \mathrm{ml} l^{-1}{ }^{35} \mathrm{~S}$-methionine (specific activity, $43475 \mathrm{TBq} \mathrm{mmol}^{-1}, \quad 1175 \mathrm{Ci} \mathrm{mmol}^{-1}$; Hartmann Analytic (Braunschweig, Germany)). After $1 \mathrm{~h}$ labelling at growth light intensities, the cells were collected by filtration and stored at $-20^{\circ} \mathrm{C}$ before protein extraction.

For pulse-chase experiments, $100-150 \mathrm{ml}$ of cultures grown at $\mathrm{LL}$ or $\mathrm{HL}$ conditions were harvested at the end of the dark phase $(07: 00 \mathrm{~h})$, the cells were collected by filtration and labelled by the addition of $20 \mu \mathrm{Ci} \mathrm{ml} l^{-1}{ }^{35} \mathrm{~S}$ methionine as described above. The collected labelled cells (pulse) were resuspended in fresh YBCHK medium with $2 \mathrm{~mm}$ of nonradioactive methionine to a Chl concentration of $1 \mu \mathrm{g} \mathrm{ml}^{-1}$, and incubated at both growth light intensities for $1-8 \mathrm{~h}$ (chase). The collected cells were stored at $-20^{\circ} \mathrm{C}$ before protein extraction. The incorporation of radioactivity into proteins was measured by scintillation counting.

To test whether the methionine content and uptake differed in LL and HL cultures, total free amino acids were isolated before and after the addition of $2 \mathrm{~mm}$ cold methionine and analysed by thin layer chromatography. Preliminary data revealed (Fig. S1, see Supporting Information) that comparable amounts of free methionine were present in LL and HL cultures. In addition, methionine uptake did not differ significantly in the two cultures (Fig. S1).

\section{Results and Discussion}

\section{Growth and visual appearance of the cells}

Contrary to many other organisms, Trichodesmium cells acclimated to HL $\left(1000 \mu \mathrm{mol} \mathrm{m} \mathrm{m}^{-2} \mathrm{~s}^{-1}\right)$ did not suffer from this irradiance in terms of growth inhibition. Compared with the $\mathrm{LL}\left(100 \mu \mathrm{mol} \mathrm{m}{ }^{-2} \mathrm{~s}^{-1}\right)$ treatment, they grew on average c. $40 \%$ faster (not shown), with a maximal growth rate of c. $0.4 \mathrm{~d}^{-1}$. This is not surprising in view of the natural habitat of this organism, where it can form blooms on the surface of tropical oceans that reach irradiances over $1000 \mu \mathrm{mol} \mathrm{m}{ }^{-2} \mathrm{~s}^{-1}$ at noon. At the same time, the growth reduction of $40 \%$ at 10 times lower irradiance means that Trichodesmium could also acclimate well to rather low irradiances, which it encounters when living deeper in the water column outside the bloom periods.

These two acclimation states were characterized by visually different appearances of the cultures and individual cells. First, the LL culture had a red-brown colour, whereas the HL culture had a yellow-brown colour (not shown). Second, the filaments of the LL culture were longer, and their cells were much thicker compared with the HL culture (Fig. 1). Further, the cells of the LL culture were less vacuolated, but filled with more thylakoids instead (Fig. 1).

\section{Nitrogen fixation}

The nitrogenase activity of the cultures grown in HL showed the pattern reported in the past for Trichodesmium (Küpper et al., 2004, 2008, 2009), whereas the pattern in the LL-grown culture was slightly different (Fig. 2). In both cultures, there was no nitrogenase activity before the start of illumination $(07: 00 \mathrm{~h})$, but, with the beginning of the light period, activity was induced $(10: 00 \mathrm{~h})$. The highest nitrogenase activity was measured in HL-acclimated culture in the middle of the light period $(13: 30 \mathrm{~h})$, and this activity decreased afterwards $(17: 00 \mathrm{~h})$. In the LL-acclimated cultures, nitrogenase activity increased gradually during the light phase, reaching a maximum in the afternoon (17:00 h) and decreasing thereafter (Fig. 2). At the 
Fig. 1 Morphology of low light $\left(100 \mu \mathrm{mol} \mathrm{m} \mathrm{m}^{-2} \mathrm{~s}^{-1}\right)$ and high light $\left(1000 \mu \mathrm{mol} \mathrm{m} \mathrm{m}^{-2} \mathrm{~s}^{-1}\right)$-acclimated filaments of Trichodesmium. The images were taken using fluorescence kinetic microscopy with bright-field illumination.
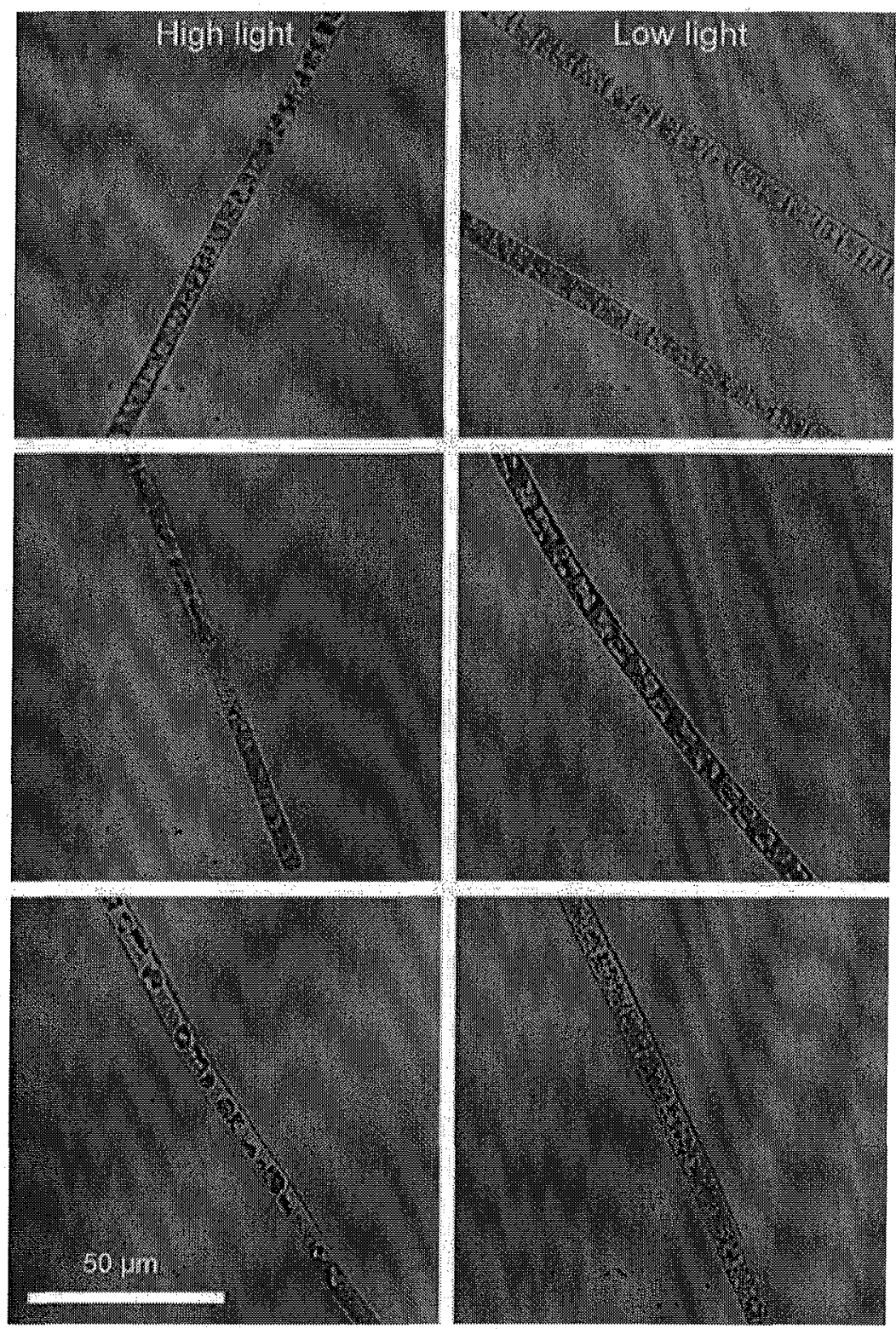

beginning of the dark period $(20: 30 \mathrm{~h})$, there was still slight nitrogenase activity in all samples. Interestingly, these diurnal activity patterns were maintained independently of the irradiance level during the $1 \mathrm{~h}$ incubation for measuring the nitrogenase activity, that is the LL culture exhibited maximal nitrogenase activity at 17:00 h even when incubated in HL conditions, and the HL culture exhibited maximal nitrogenase activity at 13:30 h even when incubated in LL conditions. This showed that nitrogenase activity is regulated not by the irradiance that the cells are currently receiving, but by the overall diurnal activity cycle that changes only slowly (range of days to weeks) during acclimation to a different irradiance level. Further, the HL conditions in the incubator (of both the $\mathrm{HL}$ and $\mathrm{LL}$ cultures) during nitrogen fixation led to a higher nitrogenase activity, even in LLacclimated culture, showing that the nitrogenase activity in this culture was light limited in terms of its dependence on energy supply from photosynthesis. In addition, in earlier experiments with the diazotrophic cyanobacteria Nostoc and Anabaena (Quesada et al., 1998), maximum irradiance (maximal natural sunlight at noon, c. $1700 \mu \mathrm{mol} \mathrm{m} \mathrm{m}^{-2} \mathrm{~s}^{-1}$ ) led to maximum nitrogenase activity. Although, in our experiments on nitrogenase activity measurement during LL incubation, both cultures performed almost equally in terms of nitrogen fixation, during HL incubation the HLacclimated culture showed higher nitrogenase activity. This 


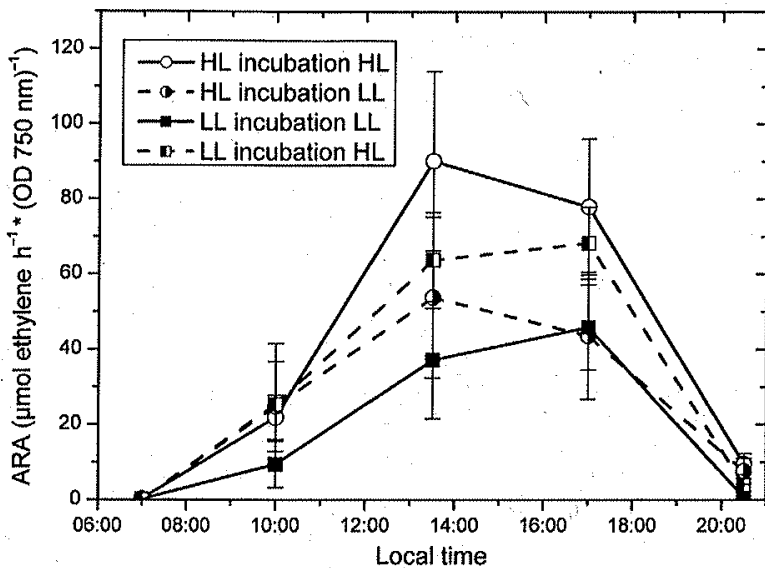

Fig. 2 Nitrogenase activity (measured as acetylene reduction activity, ARA) of the studied chemostat cultures. The cultures showed the typical daily trends; the data points shown represent the mean $( \pm S E$ ) of three measurements of each of the two independent chemostats. HL, high light; $L L$, low light.

revealed that $\mathrm{HL}$ acclimation had a greater impact on the efficiency of metabolism (usage of available light and nutrients) than did LL acclimation.

\section{Chl, carotenoid and phycobiliprotein content}

The concentrations of $\mathrm{Chl}$ and $\beta$-carotene-like pigments ( $\beta$-carotene, $\beta$-cryptoxanthin and zeaxanthin, quantified together because of identical spectra; see Küpper et al., 2007b) decreased in the HL-acclimated compared with the LL-acclimated culture. However, the decrease in $\mathrm{Chl}$ was much stronger (Fig. 3a). This makes sense because the $\beta$-carotene-like carotenoids are well known to act more as quenchers of excess excitation energy than as antennae for light harvesting. Keto-carotenoids (mainly echinenone), also known to act as quenchers of excess energy, were more abundant in HL- compared with LL-acclimated culture. As a result of the decrease in the other pigments (see above) in the HL culture, keto-carotenoids reached c. $15 \%$ of the total pigment in this culture, but only c. $6 \%$ in the LL culture.

Similar to Chls and carotenoids, the abundance of phycobiliproteins was much lower in HL- than in LL-acclimated cultures (Fig. 3b). This was caused by a strong decrease in allophycocyanin (APC), phycocyanin (PC), phycoerythrin (PE) isoform 1 (PE1) and PUBs - to about the same extent for all these phycobiliproteins (see Küpper et al., 2009 for the characterization of all Trichodesmium phycobiliproteins). The abundance of isoforms PE2 and PE3 (labelling according to Küpper $e t a l$., 2009), by contrast, hardly changed at all: that is, relative to the other isoforms, they became more abundant in HL-acclimated culture. Obviously, Trichodesmium decreases mainly the outer part of the phycobilisomes when it diminishes the energy uptake.

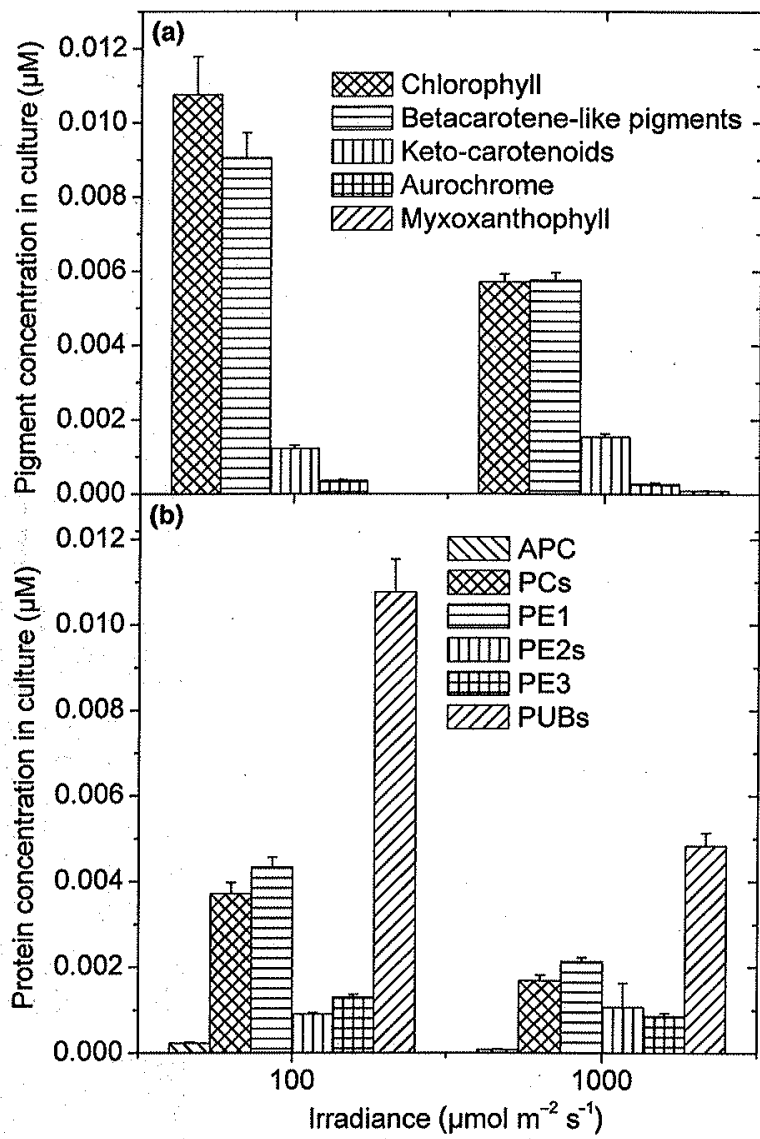

Fig. 3 Pigment (a) and phycobiliprotein (b) concentrations. Means ( + SE) of all five samples taken during the day, on at least four measuring days, for each of the at least two chemostats used for each irradiance (i.e. at least 40 samples averaged per point). Values for 'Chlorophyll' are the sum of chlorophyll $a$ and all chlorophyll $a$ degradation products (chlorophyllide a, pheophytin a and oxidation products). APC, allophycocyanin; PCs, phycocyanins; PE1, 2, 3, phycoerythrin isoforms 1,2 and 3; PUBs, phycourobilins.

\section{Abundance and turnover rates of proteins}

The steady-state level of selected proteins was measured by immunoblotting in LL- and HL-acclimated cultures at different times of the day. As shown in Fig. 4, the abundance and accumulation kinetics of several proteins differed for these two cultures.

The anti-B-PE antibody recognized two protein bands with apparent molecular masses of 18 and $15 \mathrm{kDa}$ present in both cultures (Fig. $4 \mathrm{a}$, bands $\mathrm{U}$ and $\mathrm{L}$ ). As the annotation of PE genes is not completed in the Trichodesmium genomic database (Copeland et al., 2006), an assignment of these bands to genes is currently not possible. However, these bands were also found in our study involving the purification of the phycobiliproteins from Trichodesmium: the $15 \mathrm{kDa}$ band represents isoforms $1,2 \mathrm{a}$ and $2 \mathrm{~b}$, described in this article, and the $18 \mathrm{kDa}$ band represents PE3 and PUBs 


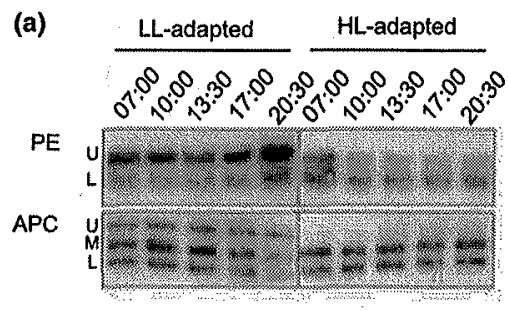

(b)

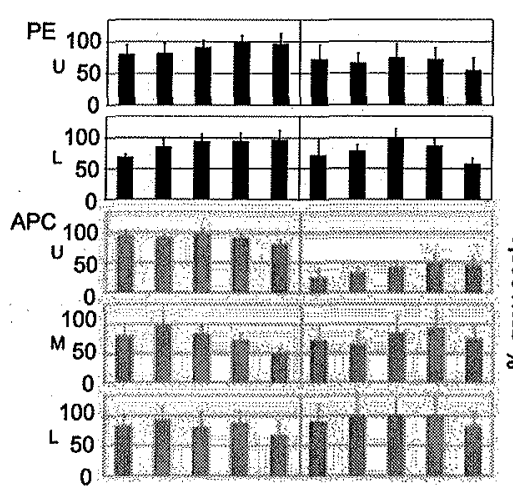

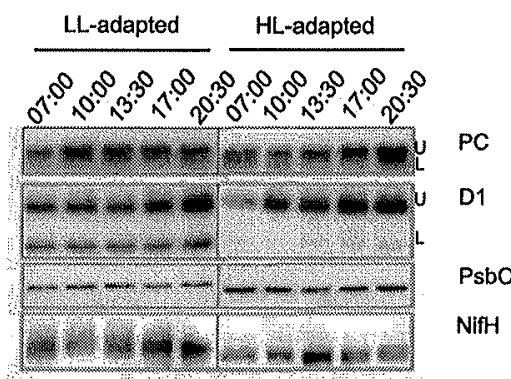

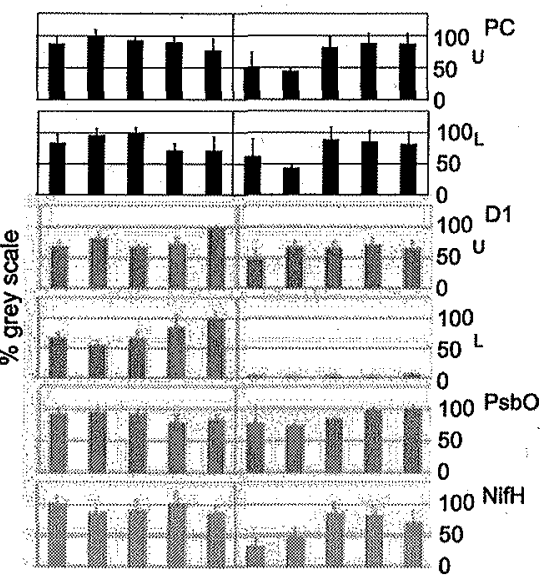

Fig. 4 Steady-state levels of selected photosynthetic and metabolic proteins in low-light (LL)-and high-light (HL)-acclimated Trichodesmium cultures assayed by immunoblotting. (a) Cells were grown in a $12 \mathrm{~h}$ light: $12 \mathrm{~h}$ dark photoperiod (light from 08:00 $\mathrm{h}$ to 20:00 h) and acclimated to LL $\left(100 \mu \mathrm{mol} \mathrm{m} \mathrm{m}^{-2} \mathrm{~s}^{-1}\right)$ or HL $\left(1000 \mu \mathrm{mol} \mathrm{m} \mathrm{m}^{-2} \mathrm{~s}^{-1}\right)$ conditions as described in Materials and Methods. Aliquots of cultures were collected during the end of the dark phase $(07: 00 \mathrm{~h})$, at the beginning $(10: 00 \mathrm{~h})$, the middle $(13: 30 \mathrm{~h})$ and the end $(17: 00 \mathrm{~h})$ of the light phase, and at the beginning of the dark phase $(20: 30 \mathrm{~h})$; proteins were isolated and used for immunoblotting. The gels were loaded on an equal protein basis. The following antibodies were applied: anti-B-phycoerythrin (PE), anti-allophycocyanin/phycocyanin (APC), anti-phycocyanin (PC), anti-D1 protein from the PSII reaction centre (D1), anti-33 kDa protein from the oxygen-evolving complex of PSII (PsbO) and anti-H subunit of nitrogenase $(\mathrm{NifH})$. L, lower band; $M$, middle band; $U$, upper band. (b) Relative grey scale values were used for a semi-quantitative estimation of immunoblot signals. Maximal șignal intensities were set as $100 \%$; the values shown are the means + SE of three independent replicate samples [the blots in (a) are from one of them]. Although the chemistry behind any detection on Western blots is not a linear function of protein abundance, the results of background-corrected densitometric scanning shown here provide an indication of the increasing/decreasing trends.

(Küpper et al., 2009). The latter react only weakly with this antibody, as described previously, but their very large amount in Trichodesmium may still mean that they are the main contribution to this band. This would also explain why the $18 \mathrm{kDa}$ protein band was the most abundant in the LL-acclimated culture and strongly reduced $(75 \%$ of the LL value) in HL-acclimated cells - this would be consistent with the decrease in PUBs detected spectroscopically (see above). Comparable immunoblot signals were obtained for the $15 \mathrm{kDa}$ band in $\mathrm{LL}$ - and $\mathrm{HL}$-acclimated cultures.

The APC antibody cross-reacted with three protein bands of c. 21, 18 and $15 \mathrm{kDa}$ in LL-acclimated cultures (Fig. 4a, bands $U, M$ and $L$ in the APC blot). According to the supplier, this antibody recognizes not only APC (one $\alpha$ and two $\beta$ subunits are encoded by the genome of Trichodesmi$u m$ ), but also PC (one $\alpha$ and one $\beta$ subunit are present in Trichodesmium; one is recognized by this antibody, labelled
PC2 in Küpper et al., 2009), and possibly also phycocyanobilin lyase (one $\alpha$ and one $\beta$ subunit are annotated in the Trichodesmium genome). Interestingly, the $21 \mathrm{kDa}$ band was reduced by $50-75 \%$ in HL- compared with LL-acclimated cells (Fig. 4b). The larger amounts of the $21 \mathrm{kDa}$ (A)PC and PE/PUB detected in LL- compared with HLacclimated cultures may be connected with the acclimative reduction of the antenna size under HL conditions. Western blots with the PC-specific antibody revealed the presence of two poorly resolved bands with apparent molecular masses of $c .15 \mathrm{kDa}$ (Fig. 4a), which may correspond to $\alpha$ $(17.4 \mathrm{kDa})$ and $\beta(18.0 \mathrm{kDa})$ subunits of PC (labelled PC1 and PC2 in our earlier publication; Küpper et al., 2009).

Three $P s b A$ genes (Ps $b A 1-3)$, encoding almost identical copies of the $32 \mathrm{kDa} D 1$ protein from the PSII reaction centre, were detected in the genome of Trichodesmium (Copeland et al., 2006). Although two copies (Terry 0182 and 
Terry 0183) are identical in their amino acid composition, the third copy (Terry 4763) encodes a protein with $99 \%$ identity to the two other copies. The D1 antibody raised against the $\mathrm{N}$-terminus of the $\mathrm{D} 1$ protein cross-reacted with two protein bands of $32 \mathrm{kDa}$ (top band marked with $\mathrm{U}$ ) and $20 \mathrm{kDa}$ (bottom band marked with $\mathrm{L}$ ) in LL-acclimated cultures (Fig. 4a). Interestingly, the lower $20 \mathrm{kDa}$ band was almost completely missing in HL-acclimated cultures (Fig. $4 \mathrm{a}, \mathrm{b}$ ). Although the top band corresponds to the molecular mass of the D1 protein in Trichodesmium, the identity of the lower band is not clear.

Similar amounts and accumulation kinetics of D1 protein were detected in LL- and HL-acclimated cultures, with the smallest amount of this protein present at the beginning of the light phase and its gradual accumulation during the day until the dark phase. Two different strategies were reported for the expression of $P s b A$ genes in cyanobacteria exposed to HL. One characterized in Synechocystis PCC6803 and Gloeobacter violaceus PCC7421 involves the increased expression of one type of $\mathrm{D} 1$ protein to cope with the increased rate of damage. The other strategy, in Synechococcus PCC7942 and Anabaena PCC7120, is to replace the existing D1 protein (D1:1 form) with a new D1 form (D1:2) for the duration of the stress, thereby altering PSII photochemistry (Sicora et al., 2009). However, all three $P_{s} b A$ genes present in Trichodesmium encode the D1:2 form, which argues against the latter strategy. Similar amounts of PsbO protein of the oxygen-evolving complex associated with PSII were detected in LL and HL cultures (Fig. 4a,b).

The amount of the $\mathrm{H}$ subunit of the nitrogenase (NifH) was highest during the peak of the nitrogen-fixing period, as observed earlier (Küpper et al., 2008): that is, $c .13: 30 \mathrm{~h}$ in the HL culture and 17:00 h in the LL culture (Fig. 4a,b).

The incorporation of radioactivity into newly synthesized proteins was measured in LL- and HL-acclimated cultures at different times of the day by pulse labelling of cells with ${ }^{35} \mathrm{~S}$-methionine. No differences in the protein pattern were observed between the collected samples after Coomassie staining (Fig. 5a, top panel). Autoradiograms (Fig. 5a, middle panel) and the counting of incorporated radioactivity into proteins (Fig. 5a, bottom panel) revealed major quantitative differences between $\mathrm{LL}$ - and HL-acclimated cultures. Only slight differences in the incorporation of radioactivity into total proteins were measured in the LL-acclimated culture at the beginning, middle and end of the light phase (Fig. 5a, bottom panel). The incorporation was $30 \%$ of the maximal value at the beginning of the light phase, decreased slightly in the middle of the day ( $27 \%$ of the maximal value) and increased again at the end of the light phase (35\% of the maximal value), when nitrogen fixation was maximal (Fig. 2). No qualitative differences in the pattern of labelled proteins were observed between these three samples (Fig. 5a, middle panel). Much higher incorporation of radioactivity into total proteins was measured for HL- acclimated cells at the beginning and in the middle, but not at the end, of the light phase, when compared with LLacclimated cultures (Fig. 5a, middle and bottom panels). The highest incorporation was measured in the middle of the light phase (this value was set as $100 \%$ ), when nitrogen fixation was maximal (Fig. 2), and incorporation decreased at the end of the light phase to $12 \%$ (Fig. $5 \mathrm{a}$, bottom panel). Interestingly, an additional protein with an apparent molecular mass of $15 \mathrm{kDa}$ was strongly labelled in HLacclimated compared with LL-acclimated cells (Fig. 5a, middle panel; protein band marked with a star).

The protein degradation rates were measured in $\mathrm{LL}$ - and HL-acclimated cultures by pulse labelling of proteins with ${ }^{35} \mathrm{~S}$-methionine at the beginning of the light phase and their chase during the whole light period. No significant differences in the protein pattern were observed between the collected samples after Coomassie staining (Fig. 5b, top panel). Autoradiograms revealed stronger protein labelling in HL-acclimated cultures when compared with LL-acclimated cells, which is in agreement with the results of pulse labelling (Fig. 5a, bottom panel). Remarkably, comparable degradation kinetics were observed for LL- and HL-acclimated cultures during the first $2 \mathrm{~h}$ of chase, where $3-5 \%$ of labelled proteins were degraded (Fig. $5 \mathrm{~b}$, bottom panel). During the 4 and $8 \mathrm{~h}$ of the chase period, $10 \%$ and $23 \%$ of labelled proteins were degraded in LL-acclimated and $21 \%$ and $46 \%$ in HL-acclimated cultures, respectively. Although the labelling of some proteins remained constant during the whole chase period, others were very unstable and degraded rapidly (Fig. 5b, middle panel, marked by arrows). Much higher protein synthesis and degradation rates measured in HL-acclimated than in LL-acclimated cultures can be related to a greater damage of proteins under $\mathrm{HL}$ conditions and their replacement by de novo synthesized molecules (Singh et al., 2008). Interestingly, the highest turnover of proteins was assayed during the period of maximal nitrogen fixation (14:30-15:30 h) in HL-acclimated cultures. This might serve as a quality control in order to keep the system healthy for efficient nitrogen fixation. Interestingly, the $15 \mathrm{kDa}$ protein strongly labelled in HL-acclimated cultures was stable during the whole chase period and degraded only at the end of the light phase (Fig. 5b, middle panel, the protein band marked by a star).

\section{Biophysics of photosynthesis}

The biophysical characteristics of the photosynthetic light reactions were studied by spectrally resolved fluorescence kinetics with subsequent deconvolution into the contributions of Chl-binding proteins (inner antenna + reaction centres) and individual phycobiliproteins, as established in our previous study (Küpper et al, 2009). This resulted in amplitudes of fluorescence kinetic parameters (e.g. $F_{0}, Q_{\mathrm{p}}$, $Q_{n p}$ ) for each of these components, shown in the $y$ axes of 

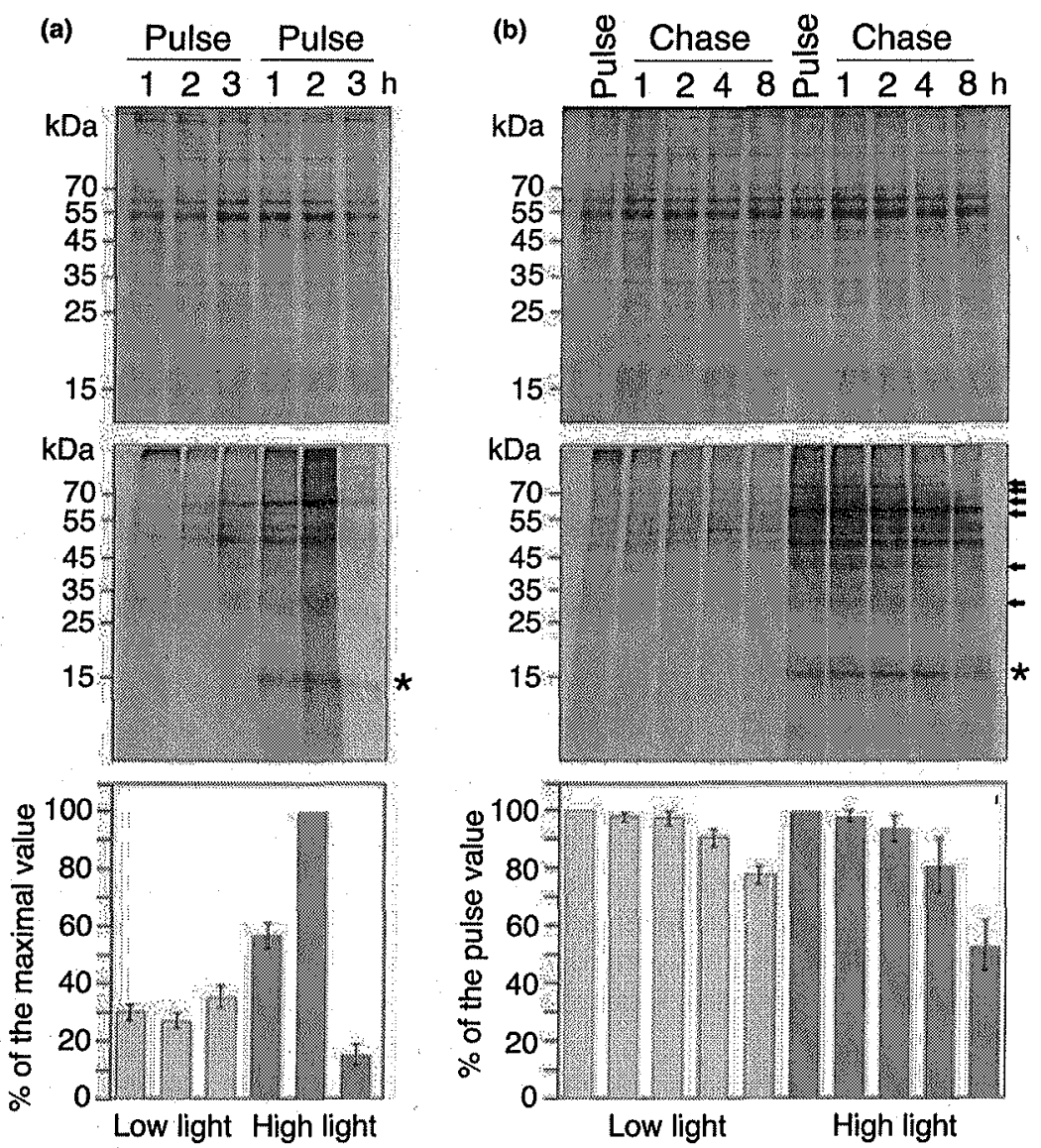

Fig. 5 Protein synthesis and degradation rates of cells from low light (LL)- and high light (HL)-acclimated cultures. (a) Cells were labelled with ${ }^{35} \mathrm{~S}$-methionine (pulse) at growth light intensities for $1 \mathrm{~h}$ at the beginning $(08: 00-09: 00 \mathrm{~h}$, line 1 ), in the middle $(14: 30-15: 30 \mathrm{~h}$, line 2) and at the end (18:00-19:00 h, line 3) of the light phase; the total proteins were extracted, separated by SDS-PAGE and stained with Coomassie (top panel). Radioactively labelled proteins were visualized by autoradiography (middle panel). The gels were loaded on an equal protein basis. A star marks a $15 \mathrm{kDa}$ protein strongly labelled in $\mathrm{HL}$-acclimated cells. The incorporation of radioactivity into total proteins was quantified by scintillation counting (bottom panel). The maximal $\mathrm{cpm}$ values were set as $100 \%$. (b) Cells were labelled with ${ }^{35} \mathrm{~S}$-methionine (pulse) at growth light intensities for $1 \mathrm{~h}$ at the beginning of the light phase (08:00-09:00 h), and then chased in the presence of nonradioactive methionine at the same light intensity for the different times indicated. Total proteins were extracted, separated by SDS-PAGE and stained with Coomassie (top panel). Radioactively labelled proteins were visualized by autoradiography (middle panel). The gels were loaded on an equal protein basis. The star marks a $15 \mathrm{kDa}$ protein strongly labelled in $\mathrm{HL}$-acclimated cells and arrows mark degraded proteins. The incorporation of radioactivity into total proteins was quantified by scintillation counting (bottom panel). The cpm values of pulse samples were set as $100 \% . \mathrm{LL}(n=3), \mathrm{HL}$ $(n=4)$.

Figs 6-8. These fluorescence parameter amplitudes were measured for each cell at each of the five measurement time points during the day ( $x$-axis of the graphs in Figs 6-8), so that the frequency of occurrence of a parameter value could be measured (encoded in colour in Figs 6-8). With this analysis, we found that acclimation to HL vs LL specifically changed the coupling of individual phycobiliproteins to the phycobilisome, and of the phycobilisomes to the reaction centres.

\section{Basic fluorescence yield $\left(F_{0}\right)$}

In principle, the fluorescence yields of all phycobiliproteins were increased in LL- compared with HL-acclimated cul- tures (Fig. 6). However, there were large differences in the extent of this increase between individual phycobiliprotein types and isoforms. The smallest changes in response to $\mathrm{HL} / \mathrm{LL}$ acclimation were observed in the fluorescence yield of PE2; this was the isoform that generally contributed the least fluorescence. The most pronounced differences between the HL and LL cultures were found for PUBs and PE1. In both cases, LL cultures exhibited a much higher fluorescence quantum yield. Furthermore, for PUBs, the peak of the elevated fluorescence quantum yield around noon was much more pronounced in LL- than in HL-acclimated cultures. This peak was caused by bright I cells, which have an increased quantum PUB yield as a result of an increased coupling of PUB to the PSII reaction centre. Although 


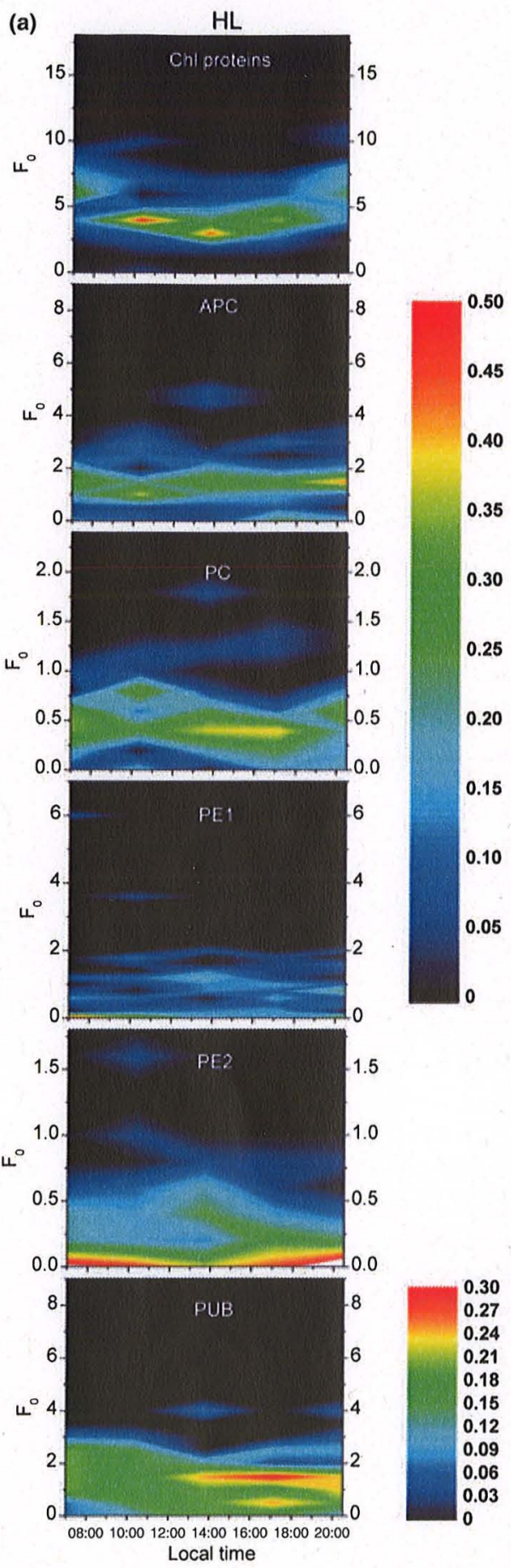

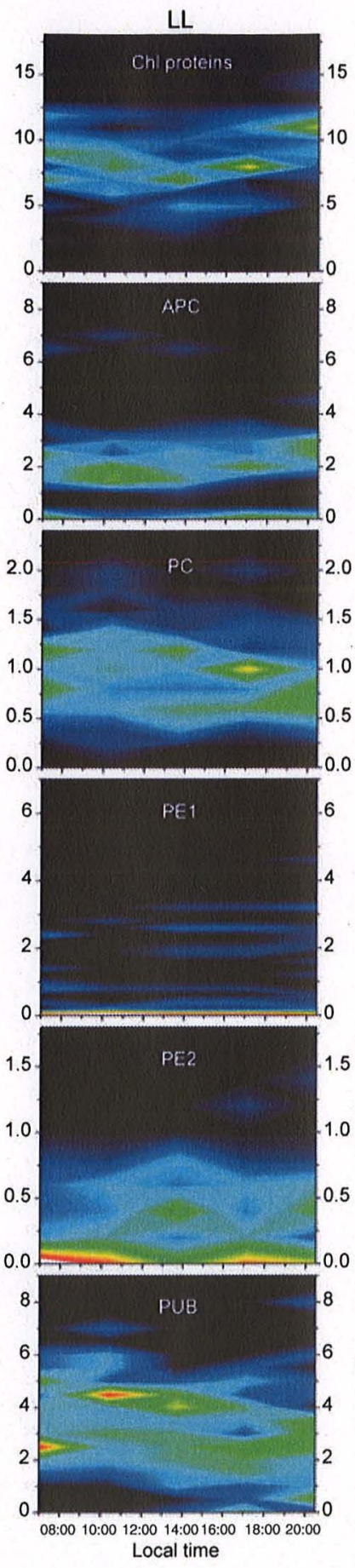

Fig. 6 Basic fluorescence yields $F_{0}$ and $F_{0 \_} U V$ : daily pattern of the relative frequencies of the values of fluorescence kinetic parameters. The separation into the contributions of the individual phycobiliproteins was performed by spectral deconvolution (see Materials and Methods for details). The numbers at the colour scales show the relative frequencies represented by each colour. The numbers labelling the $y$-axis of the panels indicate the value of the parameter. Note that, in the phycocyanin (PC) and phycourobilin (PUB) plots of the high light (HL) cultures, one bright II cell is not visible because the values were far off the scale, and stretching the scale accordingly would have made the other differences invisible. The left column of the colour maps shows HL cultures and the right column shows low light (LL) cultures. (a) $F_{0}$ measured with blue (400$505 \mathrm{~nm}$ ) excitation light. (b) $F_{0 \_}$UV measured with UV (340-390 nm) measuring light. APC, allophycocyanin; PE1, PE2, phycoerythrin isoforms 1 and 2 . large, differences between HL- and LL-acclimated cultures in the PUB contribution to $F_{0}$ were found with both types of measuring light used: blue (Fig. 6a) and UV (Fig. 6b); however, differences in PE1 could only be observed with UV excitation. This is not surprising as PE1 is not efficiently excited by blue light, so that, in blue light, it can receive energy only by fluorescence resonance energy trans- fer from PUBs, PE2 and PE3. The 365 nm UV light, by contrast, can excite all phycobiliproteins directly.

Photochemical quenching $\left(F_{\mathrm{m}}-F_{0}, F_{\mathrm{m}}{ }^{\prime}-F_{\mathrm{t}}{ }^{\prime}\right)$

In photochemical quenching $\left(F_{\mathrm{m}}-F_{0}, F_{\mathrm{m}}{ }^{\prime}-F_{\mathrm{t}}{ }^{\prime}\right)$, the first interesting observation was that, under certain conditions, 

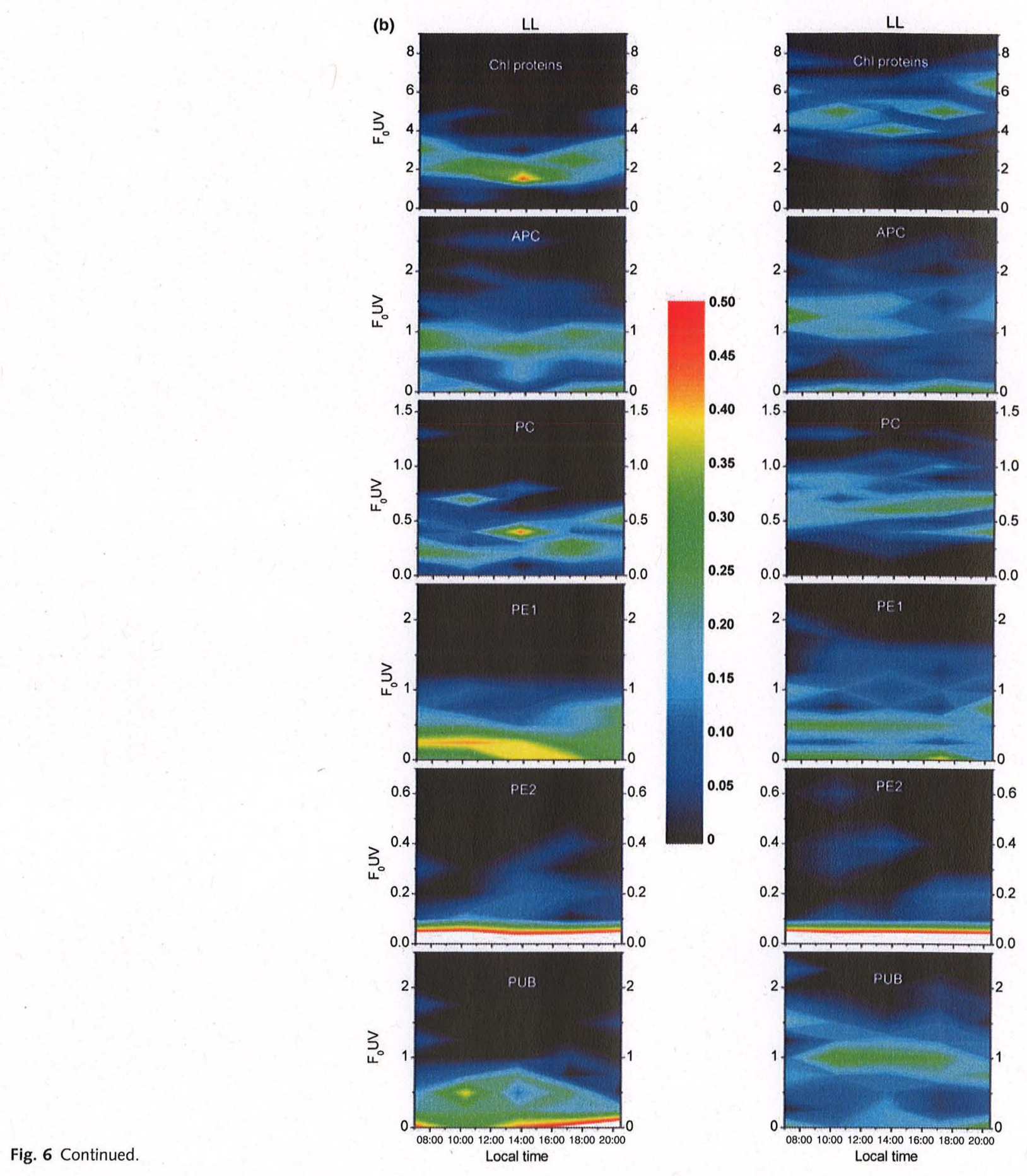

there was a contribution by phycobiliproteins, which was previously unknown. In all fluorescence kinetic measurements, PE contributed a strong peak at c. $575 \mathrm{~nm}$ to $F_{\mathrm{m}}-F_{0}$ and $F_{\mathrm{m}}{ }^{\prime}-F_{\mathrm{t}}{ }^{\prime}$. Based on the elevated $F_{0}$ in cyanobacteria compared with other photosynthetic organisms, it has so far been assumed that this is caused by phycobilisomes, and that these pigment-protein complexes do not exhibit any variable fluorescence yield (Campbell et al., 1998). Our observation of strong variable fluorescence at emission wavelengths at which $\mathrm{Chl}$ cannot possibly emit $(<650 \mathrm{~nm})$, and with the typical peak of PE (sometimes also PC and $\mathrm{PUB}$ ) emission, demonstrates that the phycobilisomes 

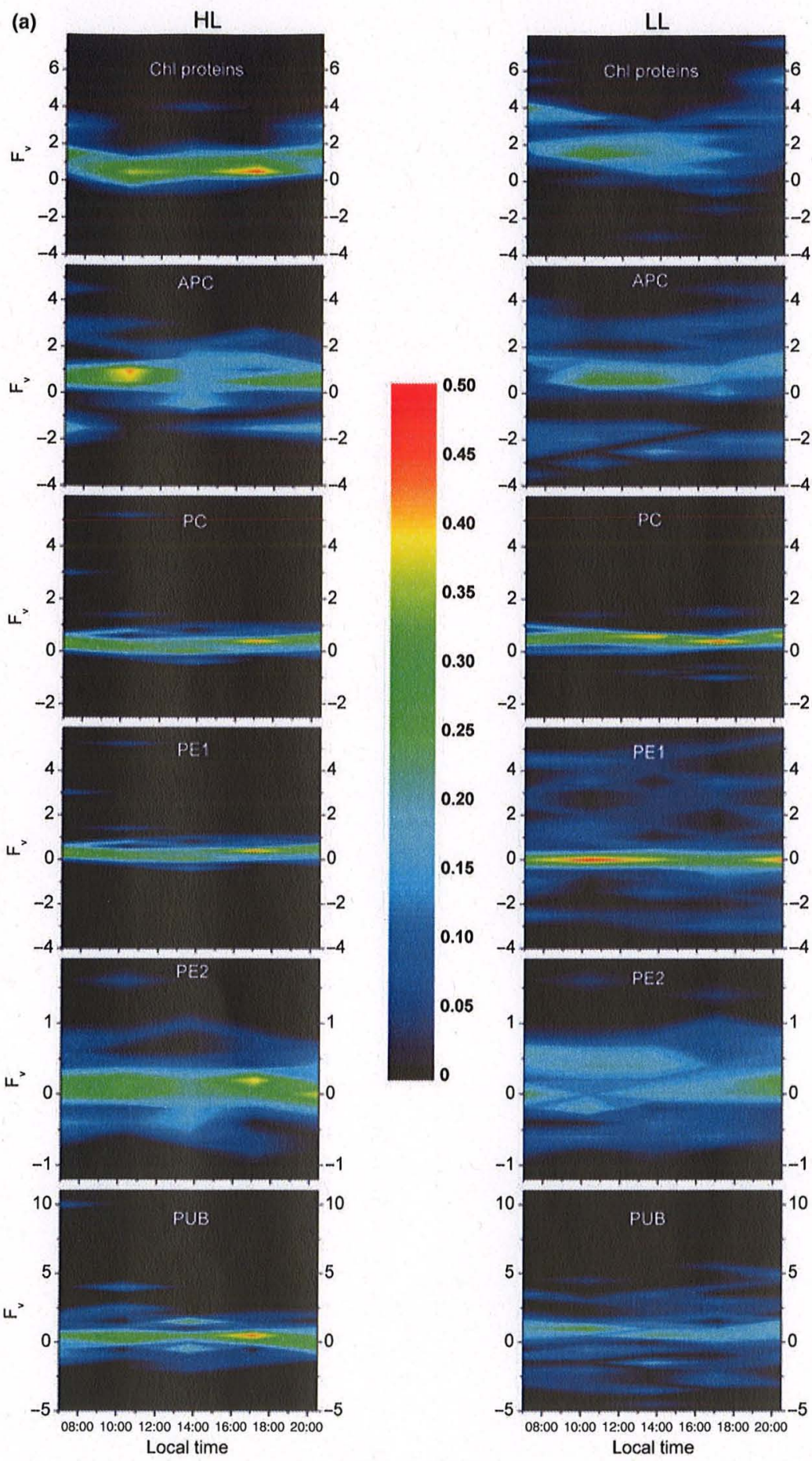

Fig. 7 Photochemical changes in the fluorescence quantum yield: daily pattern of the relative frequencies of the values of

fluorescence kinetic parameters. The separation into the contributions of the individual phycobiliproteins was performed by spectral deconvolution (see Materials and Methods for details). The numbers at the colour scales show the relative frequencies represented by each colour. The numbers labelling the $y$-axis of the panels indicate the value of the param eter. The left column of the colour maps shows high light ( $\mathrm{HL})$ cultures and the right column shows low light (LL) cultures. (a) In the dark-acclimated state at the beginning of the measurement protocol: $F_{\mathrm{v}}$. (b) At the end of the $100 \mathrm{~s}$ actinic light period of the measurement protocol: $Q_{\mathrm{p} \_} \mathrm{i}=F_{\mathrm{m} \_} \mathrm{i}-F_{\mathrm{L}} \mathrm{i}$.

of Trichodesmium are closely connected to PSII so that their fluorescence quantum yield reflects the redox status of the PSII reaction centre. This was previously known only for Chl-containing pigment-protein complexes, and it opens up the possibility to study changes in phyco- bilisome coupling by monitoring their photochemical quenching.

Although in HL-acclimated culture, the photochemical quenching of phycobiliproteins was still usually very close to zero, except for the innermost part of the phycobilisome 

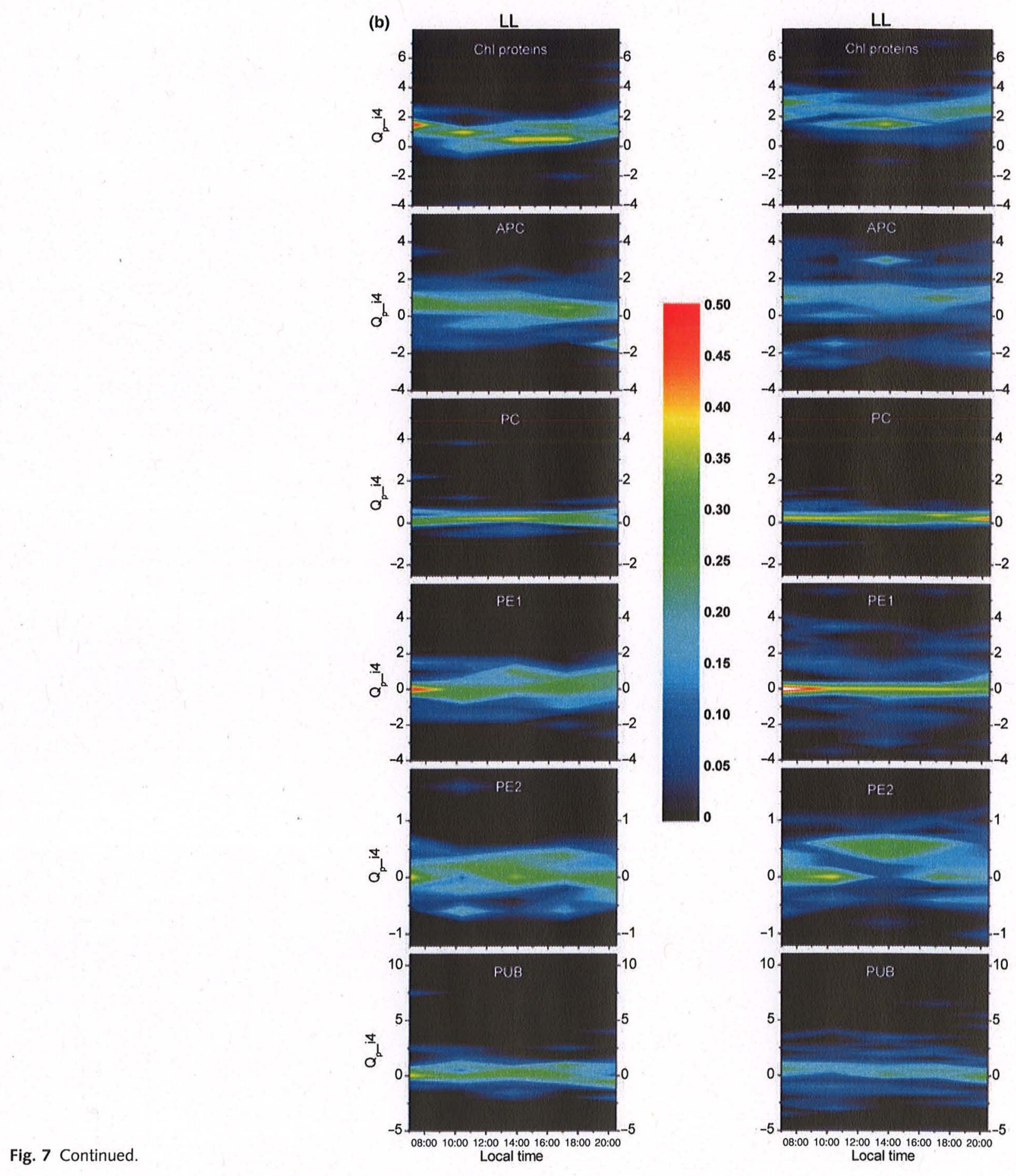

(APC), a strong contribution of PE1, PE2 and PUB to photochemical quenching was observed in LL-acclimated culture (Fig. 7). This was stronger (especially for PE2) for photochemical quenching in actinic light $\left(F_{\mathrm{m}} \mathrm{i} 4{ }_{4}-F_{\mathrm{t}-\mathrm{i}} 4\right.$, Fig. $7 b$ ) compared with photochemical quenching in the dark-adapted state $\left(F_{\mathrm{v}}=F_{\mathrm{m}}-F_{0}\right.$, Fig. 7a) and photochemical quenching after $100 \mathrm{~s}$ re-relaxation in the dark ( $F_{\mathrm{m} \_} \mathrm{r} 3-F_{\mathrm{t} \_\mathrm{r} 3}$, Fig. S2, see Supporting Information). In particular, at noon, in the LL-acclimated culture, there was a high abundance of cells with a strong contribution of PE2 
to photochemical quenching in actinic light (PE2 panel on the right side of Fig. $7 \mathrm{~b}$ ). This enhanced contribution of the outer parts of the phycobilisomes to photochemical quenching is only possible if they are so tightly coupled to the PSII reaction centre that excitons can travel back from the reaction centre with high efficiency. Thus, the occurr- ence of stronger photochemical quenching by phycobiliproteins in the LL- compared with HL-acclimated culture shows that LL acclimation involves stronger PSII association of phycobiliproteins. Further, the observation that this photochemical quenching is weaker in the dark-adapted state of the measurement $\left(F_{\mathrm{v}}\right)$ compared with the light-
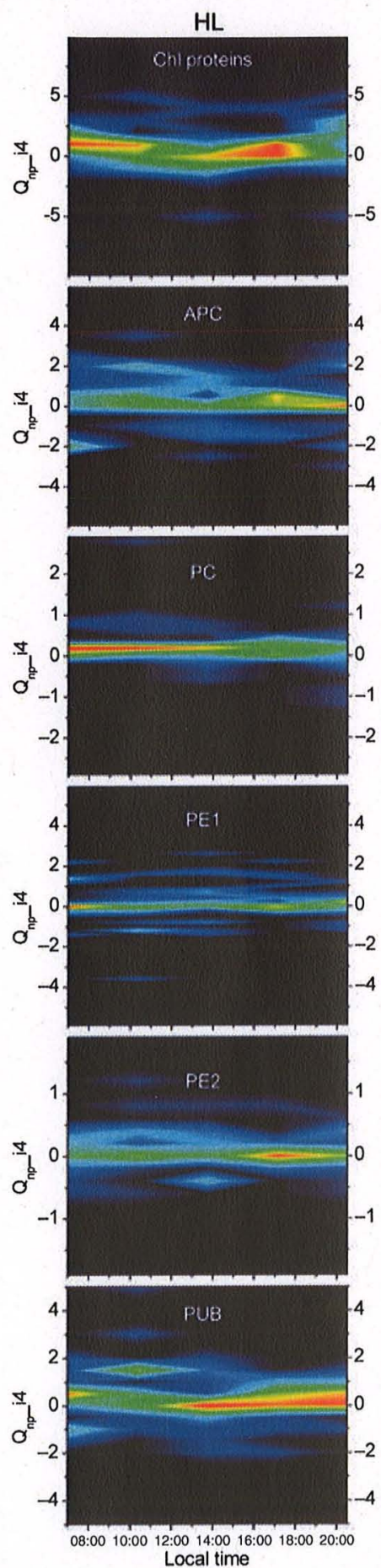

LL

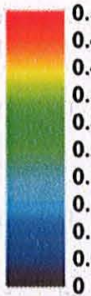

0.50

$-$
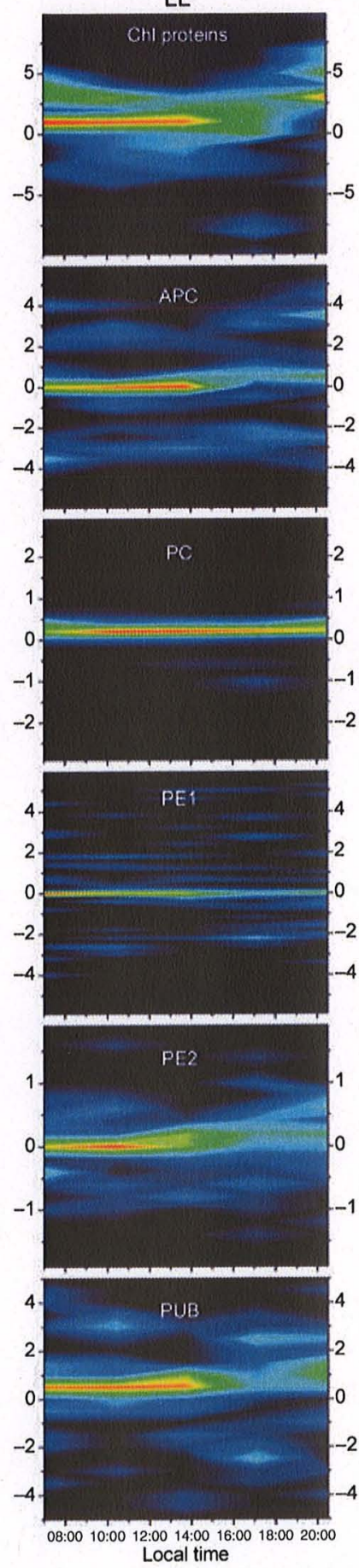

Fig. 8 Nonphotochemical fluorescence changes. Differences between the $F_{\mathrm{m}}$ and $F_{\mathrm{m}}{ }^{\prime}$ values at the end of the $100 \mathrm{~s}$ actinic light period of the measurement protocol

$\left(Q_{\mathrm{np} \_} \mathrm{i} 4=F_{\mathrm{m}}-F_{\mathrm{m} \_} \mathrm{i} 4\right)$. They show a combination of classical nonphotochemical quenching and effects caused by differential coupling of antenna complexes. The daily pattern of the relative frequencies of the values of the fluorescence kinetic parameters. The separation into the contributions of the individual phycobiliproteins was performed by spectral deconvolution (see Materials and Methods for details). The numbers at the colour scales show the relative frequencies represented by each colour. The numbers labelling the $y$-axis of the panels indicate the value of the parameter. The left column of the colour maps shows the high light (HL) cultures and the right column shows the low light (LL) cultures. 
adapted state $\left(F_{\mathrm{m}_{-}} \mathrm{i} 4-F_{\mathrm{t}-\mathrm{i} 4}\right)$ shows that this enhanced phycobilisome coupling is reversible within $<100 \mathrm{~s}$ and only occurs when electron flow through the PSII $\rightarrow$ PSI electron transport chain is already running.

\section{Nonphotochemical changes in the fluorescence quantum yield $\left(F_{\mathrm{m}}-F_{\mathrm{m}}{ }^{\prime}\right)$}

As analysed in our previous study, the nonphotochemical changes in the fluorescence quantum yield in Trichodesmi$u m$ are a mixture of nonphotochemical quenching in the sense of enhanced energy dissipation by heat emission and alterations of the coupling of individual phycobiliproteins to the phycobilisomes and of the phycobilisomes to the reaction centres. This also explains the patterns of $F_{\mathrm{m}}-F_{\mathrm{m}}$ ' observed in the present study (Fig. 8, Fig. S3, see Supporting Information). These parameters were usually positive for the Chl proteins, whereas an almost equal distribution of positive and negative values was found for the phycobiliproteins. Particularly strong (compared also with the $F_{0}$ value of the same antenna component, Fig. 6a) nonphotochemical changes in the fluorescence quantum yield, with values of the same order of magnitude as $F_{0}$ and scattered rather evenly over this amplitude range, were observed for PUB. The weakest changes were observed, by contrast,' for PC. This makes sense in view of the coupling/uncoupling events already mentioned above.

The regulation of the PSII-associated phycobiliprotein antenna size seems to be achieved predominantly by reversible coupling of PUB isoforms during the daily activity cycle (Küpper et al., 2009) and, judged by the comparison of the parameters measured here, also during acclimation to different irradiances. Coupled PUB will display a far lower fluorescence quantum yield than uncoupled PUB, and PSII-coupled PUB will exhibit more fluorescence than PSIcoupled PUB. Therefore, large changes in PUB fluorescence quantum yield were observed in response to $H L$ vs $\mathrm{LL}$ acclimation (Fig. 8) and before (Küpper et al., 2009) the daily cycle.

By contrast, $\mathrm{PC}$ is the second innermost component of phycobilisomes, just before APC. Thus, it will only show a change in quantum yield if it uncouples from APC (in vitro study; Gantt \& Lipschultz, 1973). According to our current knowledge, this only happens during transition into the (apoptotic) bright II ('very bright') state of Trichodesmium cells, as shown recently (Küpper et al., 2009). Therefore, it is not surprising that hardly any nonphotochemical changes in its quantum yield were observed (Fig. 8).

APC, the innermost part of the phycobiliproteins, displayed larger nonphotochemical changes in its fluorescence quantum yield than did PC. This can be explained by the fact that it is closest to Chl proteins, so that its quantum yield will be most influenced by their nonphotochemical quenching, and it shows a strong change in its quantum yield as a result of classical state transitions, that is migration of entire phycobilisomes between PSI and PSII, as well as phycobilisome uncoupling from the reaction centres.

\section{Conclusions}

The two light conditions used here represent the irradiances to which Trichodesmium is exposed in the ocean: the HL condition is close to the water surface and the LL condition is similar to that deeper in the water column. We found that Trichodesmium is able to acclimate well to high irradiance $\left(1000 \mu \mathrm{mol} \mathrm{m} \mathrm{m}^{-2} \mathrm{~s}^{-1}\right)$, such that, in the final acclimated state, the cells grow more rapidly than under the low irradiances $\left(100 \mu \mathrm{mol} \mathrm{m} \mathrm{m}^{-2} \mathrm{~s}^{-1}\right)$ used for Trichodesmium culture in many laboratories. According to our results, this is because Trichodesmium does not only apply the light acclimation strategies found in many other cyanobacteria (e.g. down-regulation of the synthesis of light-harvesting pigments and phycobiliproteins, up-regulation of the synthesis of light-protective carotenoids), but also the following mechanisms: (1) at low irradiances, Trichodesmium increases its cell diameter to increase the light absorption per cell; (ii) Trichodesmium can overcompensate for enhanced photoinhibitory damage to proteins at high irradiance by enhanced synthesis; (3) Trichodesmium has a previously unreported strategy of short-term light acclimation: acclimation to low irradiance levels involves an enhanced coupling of PUBs to PSII rather than PSI; (4) finally, LL phycobilisomes in Trichodesmium can be so closely coupled to PSII that their fluorescence emission can exhibit photochemical quenching, opening up a new method for studying the energy transfer within phycobilisomes and towards the PSII reaction centre.

\section{Acknowledgements}

This work was supported by grants from the Deutsche Forschungsgemeinschaft (KU 1495/2, AD-92/7-3), Konstanz University, the Ministry of Education, Youth and Sports of the Czech Republic (MSM 6007665801) and the Grant Agency of the Czech Republic (GACR 206/08/1683.).

\section{References}

Allen MB, Arnon DI. 1955. Studies on nitrogen-fixing blue-green algaegrowth and nitrogen fixation by Anabaena cylindrica Lemm. Plant Physiology 30: 366-372.

Berman-Frank I, Lundgren P, Chen Yi-B, Küpper H, Kolber Z, Bergman B, Falkowski P. 2001. Segregation of nitrogen fixation and oxygenic photosynthesis in the marine cyanobacterium Trichodesmium. Science 294: 1534-1537.

Berman-Frank I, Lundgren P, Falkowski P. 2003. Nitrogen fixation and photosynthetic oxygen evolution in cyanobacteria. Research in Microbiology 154: 157-164. 
Campbell D, Hurry V, Clarke AK, Gustafsson P, Öquist G. 1998. Chlorophyll fluorescence analysis of cyanobacterial photosynthesis and acclimation. Microbiology and Molecular Biology Reviews 62: 667-683.

Capone DG, Zehr JP, Paerl HW, Bergman B, Carpenter EJ. 1997. Trichodesmium, a globally significant marine cyanobacterium. Science 276 : $1221-1229$.

Capone DG, Burns JA, Montoya JP, Subramaniam A, Mahaffey C, Gunderson T, Michaels AF, Carpenter EJ. 2005. Nitrogen fixation by Trichodesmium spp.: an important source of new nitrogen to the tropical and subtropical North Atlantic Ocean. Global Biogeochemical Cycles 19. doi: $10.1029 / 2004 \mathrm{~GB} 002331$.

Carpenter EJ, Roenneberg T. 1995. The marine planktonic cyanobacterium Trichodesmium spp.: photosynthetic rate measurements in the $S W$ Atlantic Ocean. Marine Ecology Progress Series 118: 267-273.

Copeland A, Lucas S, Lapidus A, Barry K, Detter JC, Glavina del Rio T, Hammon N, Israni S, Dalin E, Tice $\mathrm{H}$ et al. 2006. Complete sequence of Trichodesmium erythraeum IMS101. Submitted (JUN-2006) to the EMBL/GenBank/DDBJ databases, http:/www.ncbi.nlm:nih.gov/ nuccore/CP000393.

Dilworth MJ. 1966. Acetylene reduction by nitrogen-fixing preparations from Clostridium pasteurianum. Biochimica et Biophysica Acta 127: 285294.

Fredriksson C, Bergman B. 1995. Nitrogenase quantity varies diutnally in a subset of cells within colonies of the nonheterocystous cyanobacteria Trichodesmitum spp.. Microbiology 141: 2471-2478.

Gantt E, Lipschultz CA. 1973. Energy transfer in phycobilisomes from phycoerythrin to allophycocyanin. Biochimica et Biophysica Acta 292 858-861.

Jones K. 1990. Aerobic nitrogen fixation by Lyngbya sp., a marine tropical cyanobacterium. European Journal of Phycology 25: 287-289.

Kana TM. 1993. Rapid oxygen cycling in Trichodesmium thiebautii. Limnology and Oceanography 38: 18-24.

Kïpper H, Šetlík I, Trtílek M, Nedbal L. 2000a. A microscope for twodimensional measurements of in vivo chlorophyll fluorescence kinetics using pulsed measuring light, continuous actinic light and saturating flashes. Photosynthetica 38: 553-570.

Küpper H, Ferimazova N, Šetlík I, Berman-Frank I. 2004. Traffic lights in Trichodesmium: regulation of photosynthesis for nitrogen fixation studied by chlorophyll fluorescence kinetic microscopy. Plant Physiology 135: 2120-2133.

Küpper H, Aravind P, Leitenmaier B, Trtilek M, Šetlík I. 2007a Cadmium-induced inhibition of photosynthesis and long-term acclimation to Cd-stress in the Cd hyperaccumulator Thlaspi caerulescens. New Phytologist 175: 655-674.

Küpper H, Seibert S, Aravind P. 2007b. A fast, sensitive and inexpensive alternative to analytical pigment HPLC: quantification of chlorophylls and carotenoids in crude extracts by fitting with Gauss-Peak-Spectra. Analytical Chemistry 79: 7611-7627.

Küpper H, Ś Setlík I, Seibert S, Prášil O, Śetlikova E, Strittmatter M, Levitan O, Lohscheider I, Adamska I, Berman-Frank I. 2008. Iron limitation in the marine cyanobacterium Trichodesmium reveals new insights into regulation of photosynthesis and nitrogen fixation. New Phytologist 179: 784-798.

Küpper H, Andresen E, Wiegert S, Šmek M, Leitenmaier B, Šetlík I. 2009. Reversible coupling of individual phycobiliprotein isoforms during state transitions in the cyanobacterium Trichodesmium analysed by single-cell fluorescence kinetic measurements. Biochimica et Biophysica Acta (Bioenergetics) 1787: 155-167.

Maxwell K, Johnson GN. 2000. Chlorophyll fluorescence - a practical guide. Journal of Experimental Botany 51: 659-668.

Postgate JR. 1998. Nitrogen fixation, 3rd edn. Cambridge, UK: Cambridge University Press, 112.

Quesada A, Nieva M, Leganés F, Ucha A, Martín M, Prosperi C, Fernández-Valiente E. 1998. Acclimation of cyanobacterial communities in rice fields and response of nitrogenase activity to light regime. Microbial Ecology 35: 147-155

Sicora CI, Ho FM, Salminen T, Styring S, Aro EM. 2009. Transcription of a "silent" cyanobacterial PsbA gene is induced by microaerobic conditions. Biochimica et Biophysica Acta 1787: 105-112.

Singh M, Satoh K, Yamamoto Y, Kanervo E, Aro EM. 2008. In vivo quality control in photosystem II on cyanobacteria Synechocystis sp. PCC6803: DI protein degradation and repair under the influence of light, heat and darkness. Indian Journal of Biochemistry and Biophysics 45; 237-243.

Westberry TK, Siegel DA. 2006. Spatial and temporal distribution of Trichodesmium blooms in the world's oceans. Global Biogeochemical Cycles 20. doi: 10.1029/2005GB002673.

\section{Supporting Information}

Additional supporting information may be found in the online version of this article.

Fig. S1 Analysis of free amino acid content and uptake in the high light (HL) and low light (LL) cultures by thin layer chromatography (TLC).

Fig. S2 Photochemical changes in the fluorescence quantum yield.

Fig. S3 Nonphotochemical fluorescence changes.

Please note: Wiley-Blackwell are not responsible for the content or functionality of any supporting information supplied by the authors. Any queries (other than missing material) should be directed to the New Phytologist Central Office. 